\title{
HIV health literacy and knowledge of young adults studying at a US university
}

\author{
Oxserio Benites, BSN, RN ${ }^{1 *}$,Regina L. Hale, PhD, RN, CNE ${ }^{2}$ \\ JoAnne Gay Dishman School of Nursing, Lamar University, PO Box 10081, Beaumont, Texas \\ 77710 \\ E-mail: oxydefrancis@gmail.com ${ }^{1}$,gina.hale@lamar.edu²
}

\begin{abstract}
Health literacy is an individual's understanding of and ability to make decisions related to health information. High levels of health literacy are beneficial in making informed health-related decisions. Knowledge related to HIV is relevant to society as $>36$ million individuals are estimated to be living with HIV worldwide. This research study explored HIV knowledge of young adults enrolled at a university in the US. Study participants ( $\mathrm{N}=105)$ completed the Brief HIV-Knowledge Questionnaire. While the mean survey score was 77\%, participants aged 18-19 years scored an average of 54\%. Those who had been tested for HIV scored significantly higher than those who had not been tested. Moreover, 64\% reported having an HIVnegative status but only $39 \%$ reported having been tested for HIV. The results indicate that HIV education related to transmission, protection, and testing are needed.
\end{abstract}

Keywords: HIV, health literacy, HIV knowledge, Brief HIV Knowledge Questionnaire

\section{Background}

Approximately 36.7 million people worldwide were living with HIV at the end of 2017 [1]. The Center for Disease Control (CDC), a federal health promotion agency in the US, reported 39,782 newly-diagnosed cases of HIV in 2016. Approximately $37 \%(>14,000)$ of those diagnosed with HIV in 2016 were aged 20- 29 years [2]. Texas, one of the largest states in the US, reported the highest rate of HIV acquisitions amongst young adults ages 20-29 [3]. According to the CDC [2], Texas was listed as having the third greatest number of new HIV diagnoses. Region 6 in the state of Texas, which includes the location of the research study, had the highest HIV diagnoses (1429 cases), cumulative HIV diagnoses $(50,896$ cases $)$, and number of people living with HIV $(28,909$ cases) compared to other regions of the state [3]. In addition, the Texas Surveillance Report found that the rate of HIV diagnoses steadily increased throughout the previous decade [3]. Historically, HIV education related to prevention has been a priority in the US [2]; the incidence of HIV diagnoses suggest that HIV education may have waned over the years. The purpose of this research study was to explore HIV literacy of young adults enrolled in college.

\section{Review of literature}

The World Health Organization (WHO) describes three widespread issues concerning HIV: stigma, testing, and education [4]. Stigmatising attitudes related to HIV status may persist in society [5]. Individuals with HIV may experience feelings of shame or rejection concerning their condition. They may also experience stigmatising attitudes as a result of being people who use drugs or men who have sex with men (MSM) [5]. In the research study of Derose et al, community members reported that individuals with an HIVpositive serostatus were judged harshly and faced rejection [6]. Because stigmatising attitudes limit high-risk groups from seeking health and social services, fear of this stigma may account for individuals choosing not to undergo HIV testing [7].

Being aware of one's HIV serostatus is key to accessing care, managing the condition effectively, and benefitting from interventions [4]. Therefore, individuals who engage in risky behaviours and/or have potentially been exposed to HIV should be tested. Knowing that one does not have HIV may promote behaviours aimed at protecting against HIV acquisition [8]. There are many reasons why individuals may choose not to be tested. Song et al. researched MSM who never had an HIV test. The study found that psychological barriers such as perceived low risk of HIV acquisition, fear of a positive test result, and fears of being stigmatised as MSM impeded HIV testing [9]. Others may avoid HIV testing because of legal liabilities associated with an HIV-positive status. Twenty-four states in the US require that an HIVpositive status be disclosed to sexual partners while 14 states require an HIV-positive status be disclosed if sharing needles [10]. HIV testing is an essential component in HIV prevention. Both individuals with 
and without HIV should employ strategies to prevent the spreading HIV [11]. The WHO recommends efforts aimed at testing be addressed using a multi-faceted

approach, including voluntary testing, events for testing, testing campaigns, and testing by healthcare providers [4].

There is a lack of HIV/AIDS education, which poses a serious problem for young adults [12]. While the CDC recommends 16 topics of sexual health education, including prevention of HIV and other STDs, less than half of US high schools teach all 16 topics [13]. The WHO reiterates this finding [14]. Improved access to HIV education and counselling is recommended [14].

\section{Health literacy}

Health literacy has become a popular research area over the last two decades and is recognised as a means of empowering individual health promotion by influencing health-related behaviour [15]. Several definitions of health literacy are found in the literature. A systematic review of health literacy definitions and conceptual frameworks yielded the following definition:

Health literacy is linked to literacy and entails people's knowledge, motivation and competences to access, understand, appraise, and apply health information in order to make judgments and take decisions in everyday life concerning healthcare, disease prevention and health promotion to maintain or improve quality of life during the life course [15].

High levels of health literacy benefit individuals and society as a whole. In terms of individual outcomes, Nutbeam [16] asserts that high levels of health literacy are dependent upon cognitive skills and lead to improved understanding of risks, modification of health-related behaviours, and improved selfconfidence. Low levels of health literacy, on the other hand, are associated with decreased decision-making capacity leading to engagement in risky behaviours [16].

The literature suggests a need for research regarding HIV health literacy. Wawrzyniak et al. recommend studies that focus on HIV health literacy among young adults and minority groups [17]. This study explored the HIV health literacy of young adults enrolled in college to gain insight into HIV knowledge related to HIV transmission, testing and prevention.

\section{Methods}

An exploratory descriptive design was used to investigate the HIV health literacy of young adults enrolled at a university in Southeast Texas, US. Institutional review board approval was obtained prior to data collection [AQ: is there possibly a reference number for this approval?]. (The IRB \# is 73416229, the memorandum of IRB approval will be attached to email.-OB) Recruitment flyers and social media were used to recruit participants between the ages 18-30 years, who had a current HIV-negative status or an unknown HIV status. Using SurveyMonkey, participants completed a demographic tool and the Brief HIV Knowledge Questionnaire (HIV-KQ-18) [18]. Data collection took place over a 4-week period during the Summer of 2016. To ensure anonymity, no identifying information was collected. The HIV-KQ-18 measures knowledge of sexual transmission and prevention of HIV and has an established reliability with Cronbach's alpha ranging $0.75-0.89$ [18]. Permission was obtained from the instrument developer to use the HIV-KQ-18 for this research study. Data were analysed using parametric and non-parametric statistics with the SPSS (version 23).

\section{Results}

A convenience sample of young adults $(\mathrm{N}=105)$ met the inclusion criteria and completed the online survey. The sample participants were primarily single $(89 \%)$, heterosexual (89\%), white (56\%), females $(73 \%)$, and majoring in a health science related field (52\% [AQ: Table 2 says $55 \%$, please clarify]). (55 people out of 105 participants is $52 \%$. The correct percentage is $52 \%$. $-\mathrm{OB}$ ) The mean age of the sample was 22 years; and ranged $18-29$ years. Of these, $64 \%$ reported having a negative HIV status, however, only $39 \%$ had been tested for HIV (see Tables 1-3 for participant demographic variables). The HIV-KQ-18 was evaluated for internal consistency; a Cronbach's alpha of 0.787 was obtained for this sample.

HIV health literacy was operationalised by HIV-KQ-18 scores. The mean (M) HIV-KQ-18 was 13.89 (77\%) out of a maximum score of 18 . The median score was 15.00 and correct responses ranged 2-18. A total of $63 \%$ of participants correctly answered between 14 and 18 (78-100\% respectively) questions (see Table 4). The results of the HIV-KQ-18 are displayed in Table 5 with correct answers in bold.

Correlational analysis was conducted to assess a relationship between the total score on the HIV-KQ-18 survey and demographic variables. There was a positive correlation between age and the total score on the HIV-KQ-18 $(r=0.368 ; P=0.000$ [AQ: ok insertion of ' 0 ' before decimal point?]). (Yes. - OB) A Spearman's rho analysis revealed weak to moderate correlations between the HIV-KQ-18 total score and academic major ( $r s=-0.383, P=0.00$ ) and being tested for HIV ( $r s=-0.298, P=0.002$ ). Because there was a positive correlation between age and the HIV-KQ-18 score, additional analysis was conducted to further explore this relationship. Analysis revealed that scores 
improved as the participant age increased (see Table 6). Participants aged 18-19 years scored 54\%; those aged $20-22$ years scored $75 \%$; and those aged $\geq 23$ years scored $86 \%$.

A t-test for independent samples was conducted on the HIV-KQ-18 total scores and select demographic variables. Health science majors' mean score was significantly higher than non-health science majors ( $P$ $=0.000)$. Those who had been tested for HIV scored significantly higher than those not tested for HIV $(P=$ 0.001). Non-white participants scored better than white participants, however, the difference was not statistically significant (see Table 7).

Finally, participants were asked to rate their confidence with regard to basic HIV knowledge prior to and after completing the HIV-KQ-18 survey with options ranging from very confident (4 (points-OB) [AQ: if this is score system value, please add 'points' here, thank you]) to not confident (1 (point-OB) [AQ: if this is score system value, please add 'points' here, thank you]). The mean score of Likert responses were treated as interval data and a paired samples t-test demonstrated a significant decrease in confidence rating after completing the survey $(P=0.000)$ (see Table 8).

\section{Discussion}

The aim of this study was to explore HIV health literacy among young adults enrolled in college. The research findings suggest that the study sample had low levels of HIV health literacy within the domains of prevention, transmission, and testing. While the HIVKQ-18 mean score was $77 \%$, participants scored $<75 \%$ on 9 of the 18 questions suggesting a knowledge deficit in specific areas. For example, $73 \%$ correctly identified that HIV is not transmitted by drinking after another person, only $64 \%$ knew that HIV is not transmitted via kissing, and $46 \%$ did not know if there was a preferable type of condom for preventing HIV transmission. Additionally, when asked if an HIV test will determine an HIV-positive status 1 week after exposure $12 \%$ chose true, $51 \%$ selected false, and $32 \%$ did not know.

The age-related scores in this study are of great concern. Participants aged 18-20 years of age scored significantly lower $(M=12.04)$ than participants 21 years and older $(M=14.53)$ on the HIV KQ-18 $(\mathrm{t}[103]=$ $-3.270, P=0.001)[A Q:$ these values are not in, or different from, ones shown in tables, correct?]. (Correct, the data will be attached to the email. Would it be better to make it into it's own table or to add it to table 7?- OB) Given the CDC and WHO recommendations related to high school education about HIV, the findings support a lack of knowledge amongst the younger participants in this study. Low levels of health literacy are associated with a diminished ability to make appropriate health decisions and may lead to risk-taking behaviours [16]. The CDC asserts that adolescents are likely to engage in risky behaviours of sexual origin that may result in negative outcomes including HIV acquisition. Education is recommended as an essential component in preventing risky sexual behaviour [13].

Scores on the HIV-KQ-18 were most strongly correlated with college major; health science majors scored significantly higher on the HIV-KQ-18 compared with non-science majors. While there is limited research investigating the relationship between college major and HIV knowledge, Smith et al. found that health science majors self-reported high levels of HIV knowledge as compared to other majors [19]. Universities may not include sexual health and/or amongst young college-aged adults [19].

An interesting finding is that non-white participants scored higher $(M=80 \%)$ than white participants $(M=$ $75 \%$ ) on the HIV-KQ 18 . While not statistically significant, this finding suggests that education may be heightened in the non-white population. According to the CDC, African American and Hispanic males comprised the majority of new HIV diagnoses in the US [20]. HIV knowledge in the non-white population may be acquired from family, friends, or personal experiences. Because HIV does not discriminate between age, race or gender, HIV-related education is imperative for all [21].

The literature strongly recommends education related to early HIV testing [22]. Although $64 \%$ of students reported having an HIV-negative status, only 39\% reported having been tested for HIV. This finding suggest that many participants assumed being [AQ: ok to change 'perceived to' to 'assumed being'?] (Yes.$\mathrm{OB}) \mathrm{HIV}$ negative in the absence of a diagnostic test. The disparity between a confirmed HIV-negative test and self-perception of HIV-negative status is important to discuss and warrants additional investigation. A fear of HIV stigma [5] may contribute to not getting tested [23]. Furthermore, the study population who were not tested may have assumed a negative status owing to not engaging in high-risk sexual behaviours. Interestingly, study participants who were tested for HIV scored significantly higher on the HIV-KQ-18 questionnaire (see Table 7) suggesting that higher HIV literacy promotes HIV testing. On the other hand, getting tested for HIV may in itself enhance HIV literacy as a result of education obtained during the process. Healthcare providers are encouraged engage in sexual health dialogue with patients regarding HIV testing [8], this dialogue may improve HIV-related knowledge. Nevertheless, the study findings further support the need for enhanced education related to HIV testing.

Nutbeam asserts that there is a relationship between 
confidence and health literacy. Increased confidence about a health topic is reflective of high levels of health literacy $[16,24]$. This study asked participants to rate their confidence about HIV knowledge to explore the congruence of confidence with HIV health literacy [9]. The study participants' confidence related to HIV knowledge decreased after completing the questionnaire. The decrease in confidence score may indicate a false self-assurance about HIV awareness about HIV but specific details about prevention, transmission, and testing are vague [25]. Moreover, the CDC recognises that the sexual health education topics are not being taught as recommended in schools in the US [13].

\section{Strengths, limitations and recommendations}

Strengths of this study included the use of the HIV-KQ18, a measurement with an established strong reliability. In addition, anonymity and confidentiality allowed openness and honesty with survey responses. This study had several limitations including small sample size and generalisability. During the recruitment phase, potential stigma may have been evident; flyers may have been disregarded because 'HIV' was displayed in large letters, contributing to a smaller sample size. Data were collected at one university in southeast Texas, the findings therefore cannot be generalised to the larger population.

The authors recommend additional research to further explore key findings in this study. As a knowledge deficit related to HIV was evident, research investigating HIV-related education in high schools is warranted. Qualitative research is an appropriate methodology for discovery and as such is recommended to gain additional insight on the factors motivating or precluding college-aged individuals to undergo HIV testing. Moreover, additional research is needed to better understand HIV literacy in young adults and if there is a causative link between HIV literacy and HIV testing.

\section{Conclusion}

This research reveals significant findings with regard to HIV literacy amongst young adults. The findings suggest the study sample had low levels of HIV health literacy within the domains of prevention, transmission and testing. HIV education must remain a priority as a preventive strategy for this global health issue. The adolescent and young adult populations comprise the largest segment of new HIV diagnoses in the US [2]. Enhanced educational strategies within academic institutions and the home environment are vital to curtailing HIV acquisition. knowledge at the outset. When presented with HIV questions about prevention, transmission, and testing, participants may have then recognised and acknowledged this false self-assurance by rating their confidence lower at the completion of the question. The underlying rationale for this false self-confidence may be multifaceted. Subbaro and Akhilesh assert that the media and governmental programmes promote

\section{Acknowledgements}

[AQ: would the authors like to include any acknowledgements?] (No acknowledgements.- OB)

\section{Funding}

This research was funded by McNair Scholars Program, Lamar University Beaumont, Texas.

\section{Conflicts of interests}

The authors declare no conflicts of interests. [AQ: ok insertion? If not, please declare any conflicts, thank you] (Correct, there are no conflicts of interests. - OB)

\section{References}

1. World Health Organization. Global Health Observatory, 2018. Available at: www.who.int/gho/hiv/en/ (accessed August 2020).

2. Centers for Disease Control and Prevention. HIV in the United States and dependent areas. CDC, 2018. Available at:

www.cdc.gov/hiv/statistics/overview/ataglance.html (accessed August 2020).

3. Texas Department of State Health Services TB/HIV/STD Epidemiology and Surveillance Branch. Texas HIV surveillance report. 2015 July 22; 2014 Annual Report: 28.

4. WHO. HIV programme: achieving our goals operational plan 2014-2015. Geneva, Switzerland: WHO, 2014. Available

at: apps.who.int/iris/bitstream/handle/10665/112666/978 9241507110_eng.pdf;jsessionid=FDAC5431F47A9ED97CC 29466D720019E? sequence=1 (accessed August 2020).

5. Bluthenthal RN, Palar K, Mendel P et al. Attitudes and beliefs related to HIV/AIDS in urban religious congregations: barriers and opportunities for HIV-related interventions. Soc Sci Med 2012; 74(10): 1520-1527.

6. Derose KP, Bogart LM, Kanouse DE et al. an intervention to reduce HIV-related stigma in partnership with African American and Latino churches. AIDS Educ Prev 2014; 26(1): 28-42.

7. Chesney MA, Ashley W Smith. Critical delays in HIV testing and care: the potential role of stigma. American Behavioral Scientist 1999; 42(7): 1162-1174.

8. Centers for Disease Control and Prevention. HIV testing. CDC, 2018. Available at: 
www.cdc.gov/hiv/basics/testing.html (accessed August 2020).

9. Song $Y$, Li X, Zhang $L$ et al. HIV-testing behavior among young migrant men who have sex with men (MSM) in Beijing, China. AIDS Care 2011; 23(2): 179-86.

10. Centers for Disease Control and Prevention. HIV and STD criminal laws. CDC, 2017. Available from: www.cdc.gov/hiv/policies/law/states/exposure.html (accessed August 2020).

11. Bouris A, Hill BJ, Fisher $\mathrm{K}$ et al. Mother-son communication about sex and routine human immunodeficiency virus testing among younger men of color who have sex with men. J Adolesc Health 2015; 57(5): 515-522.

12. Centers for Disease Control and Prevention. HIV and youth. CDC, 2018. Available at: www.cdc.gov/hiv/group/age/youth/index.html (accessed August 2020).

13. Centers for Disease Control and Prevention NCHHSTP Newsroom. New findings from CDC survey suggest too few schools teach prevention of HIV, STDs, and pregnancy. CDC, 2015. Available at: https: //www.cdc.gov/nchhstp/newsroom/2015/nhpcpress-release-schools-teaching-prevention.html (accessed August 2020).

14. WHO. Adolescents: health risks and solutions. WHO, 2018. Available at: http://www.who.int/newsroom/fact-sheets/detail/adolescents-health-risks-andsolutions (accessed August 2020).

15. Sørensen K, Broucke SVD, Fullam J, et al. Health literacy and public health: A systematic review and integration of definitions and models. BMC Public Health 2012; 12(1): 80-92.

16. Nutbeam D. Health literacy as a public health goal: a challenge for contemporary health education and communication strategies into the 21 st century. Health
Promotion International 2000; 15(3): 259-67.

17. Wawrzyniak AJ, Ownby RL, Mccoy K, Waldrop-Valverde D. Health Literacy: Impact on the Health of HIV-Infected Individuals. Curr HIV/AIDS Rep 2013; 10(4): 295-304.

18. Carey MP, Schroder KEE. Development and Psychometric Evaluation of the Brief HIV Knowledge Questionnaire. AIDS Educ Prev 2002; 14(2): 172-182.

19. Smith ML, Place LLL, Menn M, Wilson KL. HIV-related knowledge and perceptions by academic major: implications for university interventions. Front Public Health 2014; 2: 18.

20. Centers for Disease Control and Prevention. Basic statistics. CDC, 2018. Available at: www.cdc.gov/hiv/basics/statistics.html (accessed August 2020).

21. WHO. Frequently asked questions on HIV and AIDS : Know your HIV status. WHO Regional Office for SouthEast Asia, 2012. Available at: https: / /apps. who.int/iris/handle/10665/205125 (accessed August 2020).

22. O'Connor SJ, Manship S, Diouf $M$, et al. Barriers preventing early testing and diagnosis of HIV: results of a five-year retrospective review of clinical data for those diagnosed HIV positive in two European regions. HIV Nursing 2017; 17: 89-95.

23. Naidoo S, Taylor M. HIV health literacy, sexual behaviour and self-reports of having tested for HIV among students. Afr J AIDS Res 2015; 14(2): 107-115.

24. Shoemaker CA. Student confidence as a measure of learning in an undergraduate principles of horticultural science course. Hort Technol 2011; 20(4): 683-688.

25. Subbarao N, Akhilesh A. Knowledge and attitude about sexually transmitted infections other than HIV among college students. Indian J Sex Transm Dis AIDS 2017; 38(1): 10 .

Table 1: Demographic variables: gender, marital status, ethnicity, HIV status, and sexual orientation, $\mathrm{N}=105$

\begin{tabular}{|l|l|l|}
\hline Variable & & $\mathbf{n}(\%)$ \\
\hline Gender & Female & $77(73)$ \\
\hline Marital status & Male & $28(27)$ \\
\hline & Single & $94(27)$ \\
\hline Ethnicity & Married & $11(11)$ \\
\hline & African & $3(3)$ \\
\hline & African American & $19(18)$ \\
\hline & Asian & $10(10)$ \\
\hline & White & $59(56)$ \\
\hline Sexual orientation & Hispanic/Latino & $12(11)$ \\
\hline & Multi-cultural & $2(2)$ \\
\hline & Heterosexual & $93(89)$ \\
\hline & MSM & $2(2)$ \\
\hline
\end{tabular}




\begin{tabular}{|l|l|l|}
\hline Tested for HIV & Bisexual & $10(9)$ \\
\hline & Yes & $41(39)$ \\
\hline HIV status & No & $64(61)$ \\
\hline & & $67(64)$ \\
\hline & HIV negative & $38(36)$ \\
\hline & Unknown & \\
\hline
\end{tabular}

MSM: men who have sex with men

Table 2: Demographic variables: health science majors and non-health science majors

\begin{tabular}{|l|l|l|}
\hline Variable & & $\mathbf{n}(\%)$ \\
\hline Majors & & \\
\hline & Health science & $55(52)$ \\
\hline & Non-health science & $50(48)$ \\
\hline
\end{tabular}

Table 3: Demographic variable: college majors

\begin{tabular}{|l|l|}
\hline College major & $\boldsymbol{n}(\%)$ \\
\hline Accounting & $2(2)$ \\
Applied arts and science & $1(1)$ \\
\hline Audiology/speech pathology & $5(5)$ \\
\hline Biochemistry & $1(1)$ \\
Biology & $8(7)$ \\
Business & $4(4)$ \\
\hline Computer science & $1(1)$ \\
Criminal justice/political science & $4(4)$ \\
Education & $5(5)$ \\
\hline Engineering & $13(12)$ \\
\hline Exercise science and fitness & $1(1)$ \\
\hline FSCS/fashion merchandising & $2(2)$ \\
\hline Graphic design & $1(1)$ \\
\hline Hospitality administration & $1(1)$ \\
\hline Human resource management & $1(1)$ \\
\hline Language & $2(2)$ \\
\hline Mathematics & $1(1)$ \\
\hline Nursing & $40(38)$ \\
\hline Psychology & $10(9)$ \\
Social work & $1(1)$ \\
\hline Sociology & $1(1)$ \\
\hline
\end{tabular}

FSCS: [AQ: please provide definition of 'FSCS' thank you] (There was no "FSCS on the table we submitted, I am not sure how that was added. -OB)

Table 4: HIV-KQ-18 scores [AQ: ok rewording of column headings?] (Yes.-OB)

\begin{tabular}{ll}
$\begin{array}{l}\text { HIV-KQ-18 questions correctly answered, } \boldsymbol{n} \\
(\%)\end{array}$ & $\begin{array}{l}\text { Total partici } \\
\boldsymbol{n}(\%) \\
(\mathbf{N}=105)\end{array}$ \\
\hline $2-6(11-33)$ & $5(4.8)$ \\
$7-9(39-50)$ & $8(7.6)$ \\
$10-13(55-72)$ & $26(24.8)$ \\
$14-15(78-83)$ & $22(21)$ \\
$16-18(88-100)$ & $44(41.9)$
\end{tabular}

HIV-KQ-18: HIV-Knowledge Questionnaire 
Table 5: HIV-Knowledge Questionnaire (HIV-KQ-18) results

\begin{tabular}{|c|c|c|c|}
\hline Questions & $\begin{array}{l}\text { True* }^{*} \\
n(\%)\end{array}$ & $\begin{array}{l}\text { False* }^{*} \\
n(\%)\end{array}$ & $\begin{array}{l}\text { I don't know } \\
n(\%)\end{array}$ \\
\hline 1. Coughing and sneezing DO NOT spread HIV & $85(77)$ & $16(14)$ & $6(5)$ \\
\hline $\begin{array}{l}\text { 2. A person can get HIV by sharing a glass of water with someone who } \\
\text { has HIV }\end{array}$ & $16(14)$ & $81(73)$ & $10(9)$ \\
\hline $\begin{array}{l}\text { 3. Pulling out the penis before a man climaxes/cums keeps a woman } \\
\text { from getting HIV during sex }\end{array}$ & $3(3)$ & $94(85)$ & $9(8)$ \\
\hline 4. A woman can get HIV if she has anal sex with a man & $87(78)$ & $5(5)$ & $13(12)$ \\
\hline $\begin{array}{l}\text { 5. Showering, or washing one's genitals/private parts, after sex keeps a } \\
\text { person from getting HIV }\end{array}$ & 2(2) & $95(86)$ & $8(7)$ \\
\hline 6. All pregnant women infected with HIV will have babies born with AIDS & $14(13)$ & $73(66)$ & $18(16)$ \\
\hline $\begin{array}{l}\text { 7. People who have been infected with HIV quickly show serious signs } \\
\text { of being infected }\end{array}$ & $1(1)$ & $95(86)$ & $9(8)$ \\
\hline 8. There is a vaccine that can stop adults from getting HIV & $13(12)$ & $74(67)$ & $18(16)$ \\
\hline $\begin{array}{l}\text { 9. People are likely to get HIV by deep kissing, putting their tongue in } \\
\text { their partner's mouth, if their partner has HIV }\end{array}$ & 21 (19) & $71(64)$ & $13(12)$ \\
\hline 10. A woman cannot get HIV if she has sex during her period & $0(0)$ & $97(87)$ & $8(7)$ \\
\hline $\begin{array}{l}\text { 11. There is a female condom that can help decrease a woman's chance } \\
\text { of getting HIV }\end{array}$ & $82(74)$ & $7(6)$ & $16(14)$ \\
\hline $\begin{array}{l}\text { 12. A natural skin condom works better against HIV than does a latex } \\
\text { condom }\end{array}$ & $2(2)$ & $52(47)$ & $51(46)$ \\
\hline 13. A person will NOT get HIV if she or he is taking antibiotics & $0(0)$ & $85(77)$ & $20(18)$ \\
\hline $\begin{array}{l}\text { 14. Having sex with more than one partner can increase a person's } \\
\text { chance of being infected with HIV }\end{array}$ & $101(91)$ & $2(2)$ & $2(2)$ \\
\hline $\begin{array}{l}\text { 15. Taking a test for HIV } 1 \text { week after having sex will tell a person if she } \\
\text { or he has HIV }\end{array}$ & $13(12)$ & $56(51)$ & $36(32)$ \\
\hline $\begin{array}{l}\text { 16. A person can get HIV by sitting in a hot tub or a swimming pool with } \\
\text { a person who has HIV }\end{array}$ & $3(3)$ & $83(75)$ & $19(17)$ \\
\hline 17. A person can get HIV from oral sex & $68(61)$ & $13(12)$ & $24(22)$ \\
\hline $\begin{array}{l}\text { 18. Using Vaseline or baby oil with condoms lowers the chance of } \\
\text { getting HIV }\end{array}$ & $1(1)$ & $81(73)$ & $23(21)$ \\
\hline
\end{tabular}

${ }^{*}$ Correct answers displayed in bold.

Table 6: HIV-KQ-18 scores and age

\begin{tabular}{|l|l|}
\hline Age (years) & HIV-KQ-18 mean and percentage scores \\
\hline $18-19(n=10)$ & $9.8(54 \%)$ \\
\hline $20-22(n=56)$ & $13.53(75 \%)$ \\
\hline$\geq 23(n=39)$ & $15.51(86 \%)$ \\
\hline
\end{tabular}

HIV-KQ-18: HIV-Knowledge Questionnaire

Table 7: Difference in means between HIV-KQ 18 and demographic variables

\begin{tabular}{|c|c|c|c|c|c|}
\hline Variable & Characteristic & $n$ & Mean (SD) & $t$ & $P$-value \\
\hline \multicolumn{6}{|l|}{ Gender } \\
\hline & Female & 77 & $14.30(3.48)$ & $t(103)=-1.549$ & 0.048 \\
\hline & Male & 28 & $12.75(3.62)$ & & \\
\hline \multicolumn{6}{|l|}{ Ethnicity } \\
\hline & White & 59 & 13.53 (3.99) & $t(103)=-1.175$ & 0.243 \\
\hline & Non-white & 46 & $14.35(2.91)$ & & \\
\hline \multicolumn{6}{|l|}{ Major } \\
\hline & Health science & 54 & $15.13(2.83)$ & $t(102)=3.946$ & 0.000 \\
\hline & Non-health science & 50 & $12.52(3.82)$ & & \\
\hline \multicolumn{6}{|l|}{ HIV testing } \\
\hline & Tested & 41 & $15.20(2.62)$ & $t(103)=3.404$ & 0.001 \\
\hline & Not tested & 64 & $13.05(3.84)$ & & \\
\hline \multicolumn{6}{|l|}{ Age } \\
\hline & $\begin{array}{l}18-20 \text { years } \\
\geq 21 \text { years }\end{array}$ & $\begin{array}{l}27 \\
78\end{array}$ & $\begin{array}{l}12.04(4.15) \\
14.53(3.12)\end{array}$ & $t(103)=-3.270$ & 0.001 \\
\hline
\end{tabular}

HIV-KQ-18: HIV-Knowledge Questionnaire 
Table 8: Confidence Scores [AQ: 'score?] (Yes.-OB) before and after completing questionnaire

\begin{tabular}{|l|l|l|l|}
\hline Variable & Mean (SD) & $\mathbf{t}$ & $\boldsymbol{P}$-value \\
\hline Confidence before & $2.58(0.988)$ & 4.364 & 0.000 \\
\hline Confidence after & $2.27(0.943)$ & & \\
\hline
\end{tabular}

SD: standard deviation 